Artigo original

Hegemonia - Revista Eletrônica de Relações Internacionais do Centro Universitário Unieuro

ISSN: $1809-1261$

UNIEURO, Brasília, número 10, 2012, pp. 49-76.

Recebido em: 13/4/2012

Revisado em: 8/5/2012

Aprovado em: 19/6/2012

\title{
A importância do prévio estudo de mercado quando da implantação de empresas no exterior
}

\author{
SOUZA, Gerson Martins de ${ }^{1}$ e CANDIDO, Maiane Souza ${ }^{2}$ \\ Nenhuma empresa deve tratar de introduzir-se no mercado \\ externo até que esteja \\ preparada. (Nicola Minervini)
}

RESUMO: Este artigo abordou a importância do prévio estudo de mercado quando da implantação de empresas no exterior. Cada vez mais empresas brasileiras estão buscando oportunidades de crescimento em mercados externos, o que exige atenção e preparo, pois, se aventurar em mercados desconhecidos sem um prévio conhecimento do mesmo pode acarretar em prejuízos e perda de tempo. O objetivo deste trabalho foi estudar a importância da análise de mercado antes da empresa buscar se estabelecer no exterior e analisar as variáveis mercadológicas que podem interferir neste processo. Foi realizada uma pesquisa exploratória bibliográfica para embasamento de todo o artigo. A partir da pesquisa desenvolvida é possível constatar que são diversas as variáveis que podem entravar a implantação de uma empresa no exterior, mas com uma análise preliminar de cada uma é possível se preparar e tomar decisões precisas.

1 Bacharel em relações Internacionais, mestre em Ciência Política, professo de Comercio Exterior e Estudo de Comércios Nacionais e Internacionais - FAPRO Ceilaândia.

$2 \quad$ Bacharel em Administração - FAPRO - Ceilândia. 
Artigo original

Hegemonia - Revista Eletrônica de Relações Internacionais do Centro Universitário Unieuro

ISSN: $1809-1261$

UNIEURO, Brasília, número 10, 2012, pp. 49-76.

Palavras - chave: Estudo de mercado. Internacionalização. Variáveis mercadológicas.

ABSTRACT: This article discusses the importance of prior study of the market when the deployment of overseas companies. More and more Brazilian companies are seeking growth opportunities in foreign markets, which require attention, since venturing into unknown markets without prior knowledge of it, can cause significant damage and wasted time. The objective of this study is to demonstrate the importance of market analysis before the company seeking to establish overseas marketing and analyze the variables that can interfere with this process. It was made an exploratory research literature to support the entire article. From the research undertaken it is clear that there are several variables that may hinder the establishment of an overseas company, but a preliminary analysis of each one can be prepared and make accurate decisions.

KEYWORDS: Market research. Internationalisation. Marketing variables.

INTRODUÇÃO

Cada vez mais empresas brasileiras estão buscando oportunidades de crescimento em mercados externos, o que exige uma maior atenção, pois se aventurar em mercados desconhecidos sem um prévio conhecimento do que lhe espera pode acarretar em prejuízos e perda de tempo. 
Artigo original

Hegemonia - Revista Eletrônica de Relações Internacionais do Centro Universitário Unieuro

ISSN: $1809-1261$

UNIEURO, Brasília, número 10, 2012, pp. 49-76.

Este trabalho se justifica por ser relevante tanto para a sociedade como para a academia de administração, mais especificamente para o desenvolvimento do comércio exterior.

Segundo $^{3}$ dados do IBGE do ano de 2009, cerca de 70 \% das empresas que abandonam suas atividades e fecham as portas são por falta de preparo e controle gerencial.

Portanto, o objetivo deste trabalho é estudar a importância do prévio estudo de mercado quando da implantação de empresas no exterior. O estudo visa analisar a importância de um estudo de mercado preliminar para evitar problemas por falta de conhecimento do país em que se pretende atuar e descrever as variáveis mercadológicas que podem interferir na implantação das empresas no exterior.

No caso de empresas que buscam a internacionalização, as peculiaridades de entrave começam no processo de escolha de mercados. O presente estudo busca entender as variáveis que podem entravar ou até mesmo ajudar as empresas a se estabelecerem no exterior.

Segundo SOBEET (2007), a partir dos anos 90, muitas empresas brasileiras de viram forçadas a buscar mercados internacionais para compensar a perda efetiva de market share no mercado local e a redução da rentabilidade das operações

3 Disponível em:

http://www.ibge.gov.br/home/estatistica/pesquisas/pesquisa_resultados.php?id_pe squisa $=9$. 
Artigo original

Hegemonia - Revista Eletrônica de Relações Internacionais do Centro Universitário Unieuro

ISSN: $1809-1261$

UNIEURO, Brasília, número 10, 2012, pp. 49-76.

domésticas. Desde então, cada vez mais as empresas brasileiras vêm mostrando um alto potencial para internacionalizar suas operações.

Com o auxílio de diversas políticas de promoção à exportação, várias empresas entenderam que investir em mercados internacionais é uma chance de alavancar seus negócios.

Portanto, Minervini (1997) afirma que quando um empresário decide exportar, nem sempre esta decisão é tomada após análise do mercado. Geralmente a decisão vem de alguma similaridade que existe entre os países. Exemplo disto é um empresário decidir exportar para Portugal por ser o idioma semelhante, ou querer operar em lugares onde a distância geográfica é menor. Este tipo de atitude pode trazer complicações, pois em cada mercado existem suas peculiaridades, o que exige muito cuidado antes de qualquer investimento.

Ainda segundo o autor, a empresa deve se preparar com muita antecedência para exportar, para que tal ação não se transforme em uma aventura, mas um processo baseado em análises e decisões comprometidas com o sucesso.

Já para Ferrell (2009, p. 7), em seu nível mais básico, mercado é um conjunto de compradores e vendedores; e para cada empresa que busca aventurar-se em mercados internacionais, é de suprema importância à análise de todo este conjunto.

Portanto, seguindo o pensamento do autor, a empresa deve definir a sua política de atuação; em primeiro lugar deverá ser feito um estudo de mercado, que vem a ser o ato de recolher e analisar 
Artigo original

Hegemonia - Revista Eletrônica de Relações Internacionais do Centro Universitário Unieuro

ISSN: $1809-1261$

UNIEURO, Brasília, número 10, 2012, pp. 49-76.

dados a respeito do mercado em que se deseja atuar. Realizando este estudo, a empresa poderá conhecer todas as peculiaridades e preferências dos seus prováveis consumidores.

Mais uma vez Favero (1999), salienta que para um estudo de mercado bem elaborado, o empresário deverá observar todas as variáveis mercadológicas, o que no futuro pode ser bom ou ruim para os negócios da empresa.

Palacios (2009) nos explica que cada mercado é composto por diversas variáveis e, é de suma importância a análise individual de cada uma. Essas variações podem ser de ordem econômica, tecnológica, sociocultural, legal e política. Também podem interferir diretamente a moeda e a concorrência. Identificar e estudar cada um destes fatores é um aspecto que pode afetar o relacionamento da empresa com seus consumidores em mercados internacionais. Para ficar mais claro como cada fator pode interferir tanto negativamente como positivamente em negócios no exterior, se faz necessário à análise individual de cada um.

A metodologia utilizada para o desenvolvimento deste artigo foi a pesquisa de cunho bibliográfico, com base em livros, artigos, internet, autores conceituados e periódicos.

O presente artigo aborda a importância do estudo de mercado quando da implantação de empresas no exterior e para melhor análise do tema, são abordadas as variáveis mercadológicas que exercem influência sobre o poder de internacionalização das empresas. 
Artigo original

Hegemonia - Revista Eletrônica de Relações Internacionais do Centro Universitário Unieuro

ISSN: $1809-1261$

UNIEURO, Brasília, número 10, 2012, pp. 49-76.

1.DESENVOLVIMENTO TEÓRICO

Poucas são as empresas que nascem com a intenção de globalizar suas operações. Segundo Sobeet (2007), a maioria tem apenas a intenção de atuar no mercado doméstico. Mas com o passar do tempo, algumas empresas desenvolvem capacidades que vão além do que o mercado local exige, criando assim oportunidades de expansão para o mercado internacional, que está cada vez mais acessível.

Sobeet (2007) destaca ainda que é possível identificar claras vantagens nos negócios e investimentos no mercado internacional. As empresas que participam dessas atividades costumam apresentar indicadores superiores de rentabilidade e eficiência e taxas maiores de crescimento nas vendas. Por isso, entre as empresas brasileiras, existe uma crescente percepção da necessidade de aproveitar as oportunidades que surgem de internacionalização das atividades.

1.1- O que é internacionalização e suas vantagens?

Para Sobeet (2007) podemos entender que internacionalização é um fenômeno amplo, que compreende desde a exportação de produtos e serviços até a sua produção direta no mercado externo, passando por fases intermediárias de crescente comprometimento 
Artigo original

Hegemonia - Revista Eletrônica de Relações Internacionais do Centro Universitário Unieuro

ISSN: $1809-1261$

UNIEURO, Brasília, número 10, 2012, pp. 49-76.

com esse mercado. Mas até uma empresa estar totalmente comprometida, há um longo caminho a ser percorrido.

Já Minervini (1997) destaca que uma das primeiras coisas a se avaliar antes de se aventurar no exterior, é a capacidade de internacionalização da organização. Se não houver esta capacidade, é necessário que se faça uma adequação da empresa e dos produtos, pois uma empresa despreparada não terá a menor chance em mercados desconhecidos e altamente competitivos.

Segundo Sobeet (2007) a empresa internacionalizada, ou com algum grau de internacionalização, normalmente tem produtividade e rentabilidade maior do que as outras empresas do setor.

São claras as vantagens para as empresas que conseguem se estabelecer no exterior, mas para esta transição ser feita com sucesso, é necessário um investimento preliminar em estudos de mercado para obtenção de informações relevantes a respeito do mercado-alvo.

1.2 - Estudo de mercado

Segundo Minervini (1997) para um futuro exportador é importante fazer uma prévia seleção de possíveis mercados em que poderá atuar. Esta tarefa é bastante complexa, mas após esta seleção preliminar fica mais fácil filtrar os mercados mais atraentes, e 
Artigo original

Hegemonia - Revista Eletrônica de Relações Internacionais do Centro Universitário Unieuro

ISSN: $1809-1261$

UNIEURO, Brasília, número 10, 2012, pp. 49-76.

então fazer uma análise detalhada de cada um para avaliar a viabilidade de investimento no mercado de maior potencial.

De acordo ainda com Minervini (1997) podemos definir estudo de mercado como a recolha e análise de informações para avaliar as condicionalidades e oportunidades de mercado. É um estudo que tem como objetivo selecionar mercados para a venda de produtos, identificar tendências e expectativas, reconhecer a concorrência, conhecer e avaliar oportunidades e ameaças, determinar as perspectivas de venda do produto no mercado externo e indicar a maneira de se obter os melhores resultados.

Para Favero (1999) a pesquisa é um instrumento valioso de recolhimento de informações e, nos permite encontrar o caminho mais adequado para tomar todas as decisões necessárias. A decisão de entrar em determinado mercado externo deve ser baseada mais em pesquisa e menos em feeling. Por mais que a empresa tenha sucesso no mercado interno, ao entrar no exterior ela será apenas uma aprendiz. Ainda para o autor, antes de iniciar qualquer atividade na área de exportação, é recomendável conhecer as barreiras ou dificuldades que poderão surgir, de maneira que haja preparação para superá-las ou, no mínimo contorná-las.

Já para Cateora (2009) pesquisa de mercado internacional ${ }^{4}$ é um investimento imprescindível que leva à economia de recursos e

4 A pesquisa de mercado internacional permite identificar dentro de um país, suas práticas comerciais, os aspectos culturais, econômicos, tecnológicos, legais e políticos. Permite ainda obter dados estatísticos necessários para a familiarização com o país em que se deseja atuar. 
Artigo original

Hegemonia - Revista Eletrônica de Relações Internacionais do Centro Universitário Unieuro

ISSN: $1809-1261$

UNIEURO, Brasília, número 10, 2012, pp. 49-76.

fornece informações essenciais para o relacionamento com o mercado consumidor. Somente após uma prévia investigação de mercado é possível identificar as condições mais rentáveis para se entrar no mesmo com poucos riscos e o mínimo de custos.

Segundo Minervini (1997) na fase de pesquisa do mercado exterior, a empresa deve se empenhar em conhecer, na medida do possível, todas as características do país-alvo. Estas características abrangem aspectos, tais como: Moeda, concorrência, aspectos econômicos, tecnológicos, legais, políticos e sócio-culturais. Todas estas variáveis serão estudadas no decorrer do trabalho para melhor compreensão de sua importância.

2 - Pesquisa referente ao Mercado Internacional - Variáveis Mercadológicas

\section{1 - Fatores econômicos}

Se existe um ponto comum sobre qualquer economia, este é o de que ela vai mudar inevitavelmente. Cabe aos empresários se manterem atualizados a respeito do mercado em que desejam se estabelecer.

Para Minervini (1997) é necessário traçar o perfil do mercado onde se deseja atuar, e dentro do quadro econômico deve-se analisar o PIB, renda per capita, inflação, moeda local, câmbio, taxas de 
Artigo original

Hegemonia - Revista Eletrônica de Relações Internacionais do Centro Universitário Unieuro

ISSN: $1809-1261$

UNIEURO, Brasília, número 10, 2012, pp. 49-76.

juros, linhas de crédito, indicadores de risco e todo o sistema financeiro. A partir da análise minuciosa de cada um destes fatores, fica mais fácil para a empresa determinar sua estratégia de atuação.

Segundo Ferrel (2009), para uma análise completa dos fatores econômicos deve-se aferir e antecipar condições como inflação, níveis de emprego e renda, taxas de juros, impostos restrições comerciais, tarifas e os estágios atual e futuro do ciclo de negócios (prosperidade, estagnação, recessão, depressão e recuperação).

Ainda segundo o autor, deve-se observar as impressões gerais dos consumidores sobre a economia e sua capacidade e disposição para consumir. A confiança do consumidor pode afetar bastante o que a empresa pode ou não fazer no mercado. Consumidores com baixa confiança podem não estar dispostos a pagar valores elevados por produtos de qualidade, mesmo que tenham capacidade.

\section{2 - Moeda}

Para Favero (1999, p. 133) os futuros exportadores devem observar a conversibilidade da moeda do país em que se deseja atuar.

Ainda segundo o autor, pode-se definir conversibilidade da moeda como a capacidade de a moeda ser aceita por todos que tem valor a receber e que decorre da certeza de que será acolhida por terceiros quando for utilizada para pagamentos. 
Artigo original

Hegemonia - Revista Eletrônica de Relações Internacionais do Centro Universitário Unieuro

ISSN: $1809-1261$

UNIEURO, Brasília, número 10, 2012, pp. 49-76.

"Moeda conversível - Aquela que é livremente aceita além das fronteiras do país emitente, em qualquer mercado e sem quaisquer restrições. Exemplos: dólar dos Estado Unidos, marco alemão, libra esterlina, franco suíço, etc.Moeda não conversível - Aquela que não permite a seu portador trocá-la livremente por outras moedas estrangeiras. Não tem aceitação internacional. Exemplos: colón costarriquenho, rúpia indiana, etc" (FAVERO, 1999, p. 133).

\section{3- Fatores tecnológicos}

Já no que se refere aos fatores tecnológicos, Sobeet (2007) afirma que um dos motivos que levam as empresas brasileiras a buscarem a internacionalização é a procura de tecnologia, tanto para aumentar sua competitividade nos mercados internacionais, quanto para fortalecer sua posição no mercado nacional.

Para Palacios (2009) no que diz respeito ao ambiente tecnológico, podemos afirmar que se trata de um elemento diretamente relacionado com os custos de produção. Um exemplo disto são os avanços na tecnologia de computação que tornaram o armazenamento e o controle de estoque nos depósitos mais barato e eficiente.

De acordo com Ferrel (2009) em alguns casos, as mudanças na tecnologia são tão profundas que tornam obsoletos os produtos de uma empresa, como aconteceu com os discos de vinil, as máquinas de escrever, as fitas cassete, entre tantos outros produtos. O 
Artigo original

Hegemonia - Revista Eletrônica de Relações Internacionais do Centro Universitário Unieuro

ISSN: $1809-1261$

UNIEURO, Brasília, número 10, 2012, pp. 49-76.

desenvolvimento tecnológico é um dos grandes responsáveis pela vida da empresa, pela qualidade dos produtos, pelo atendimento do mercado e principalmente, pelo desenvolvimento das pessoas no meio empresarial.

Não por acaso, o desenvolvimento tecnológico das empresas é fator fundamental nas decisões que envolvem a sua cadeia produtiva e as exportações. E se tratando de máquinas, a utilização de equipamentos modernos possibilita aumento da produtividade e da qualidade.

Segundo Favero (1999) ao exportar, a empresa absorve, sem ônus, uma espécie de tecnologia oculta, entendendo- se por essa expressão tudo aquilo que o importador transfere ao exportador no ato da negociação: condições do contrato, padrão de qualidade, tipos de embalagem, etc.

Ainda seguindo o mesmo raciocínio, Favero (1999) afirma que na medida em que a empresa desenvolve seus negócios no exterior, os benefícios dessa internacionalização propicia o aperfeiçoamento de métodos e técnicas industriais e comerciais, os quais poderão colocála em patamar vantajoso frente aos concorrentes internos. Ainda para o autor, sob esse enfoque, se, numa primeira etapa, a exportação representa uma alternativa rentável, numa segunda fase, gera benefícios para a empresa em termos de mercado doméstico. Esses benefícios podem ser traduzidos por preços mais competitivos, melhorias de qualidade dos produtos que fabricam e até mesmo pelo próprio aprimoramento dos métodos administrativos. 
Artigo original

Hegemonia - Revista Eletrônica de Relações Internacionais do Centro Universitário Unieuro

ISSN: $1809-1261$

UNIEURO, Brasília, número 10, 2012, pp. 49-76.

Para as empresas que buscam se destacar em mercados externos, se faz necessária a absorção de novas tecnologias, o que proporciona às empresas vantagens competitivas e uma adaptação menos turbulenta em seus mercados-alvo.

\section{4 - Fatores socioculturais}

Os fatores socioculturais definem a identidade de cada país. Identificando o que agrada o mercado-alvo, fica mais fácil se estabelecer sem maiores prejuízos.

Para Ferrell (2009), fatores socioculturais são influências sociais e culturais que causam mudanças em atitudes, crenças, normas, costumes e estilos de vida. Essas forças afetam profundamente o modo como às pessoas vivem e ajudam a determinar o que, onde, como e quando os consumidores compram os produtos de uma empresa.

Segundo Palacios (2009), é vital para um processo de internacionalização empresarial uma análise detalhada da cultura nos diferentes mercados-alvos e a adaptação da empresa a essa realidade.

Santos (1983) afirma que a cultura é uma construção histórica, seja como concepção, seja como dimensão do processo social. Ou seja, a cultura não é algo natural, não é uma decorrência de leis físicas ou biológicas. Ao contrário, a cultura é um produto coletivo da 
Artigo original

Hegemonia - Revista Eletrônica de Relações Internacionais do Centro Universitário Unieuro

ISSN: $1809-1261$

UNIEURO, Brasília, número 10, 2012, pp. 49-76.

vida humana. Isso se aplica não apenas à percepção da cultura, mas também à sua relevância, à importância que passa a ter. Aplica-se ao conteúdo de cada cultura particular, produto da história de cada sociedade.

Palacios (2009) nos desvela que a cultura é um conjunto complexo que inclui os conhecimentos, as crenças, a arte, a lei, a moral, os costumes e todas as outras capacidades e hábitos adquiridos pelo homem enquanto membro de uma sociedade. Ainda para 0 autor, compreender as diferenças culturais facilita 0 entendimento da necessidade de integração da empresa nos mercados em que atua e faz dessa integração elemento crucial de competitividade empresarial, sobretudo pela maior proximidade aos mercados em que a empresa atua, e pela maior integração de todos os stakeholders ${ }^{5}$ no projeto que a empresa se propõe a executar.

Segundo Tylor (2009), cultura 6 é todo aquele complexo que inclui o conhecimento, as crenças, a arte, a moral, a lei, os costumes e todos os outros hábitos e aptidões adquiridos pelo homem como membro da sociedade.

Ao investigarmos um pouco mais a fundo as diferenças culturais, podemos identificar os fatores mais marcantes das diferenças culturais (figura 1 ).

5 Stakeholders - todos os interessados na vida da empresa sejam eles, entre outros, os acionistas, os fornecedores, os clientes, os consumidores, os empregados e os dirigentes.

6 Existem diversas definições de cultura, mas aqui optamos por alguns autores das inúmeras publicações que se dedicam ao tema. 


\section{Artigo original}

Hegemonia - Revista Eletrônica de Relações Internacionais do Centro Universitário Unieuro

ISSN: $1809-1261$

UNIEURO, Brasília, número 10, 2012, pp. 49-76.

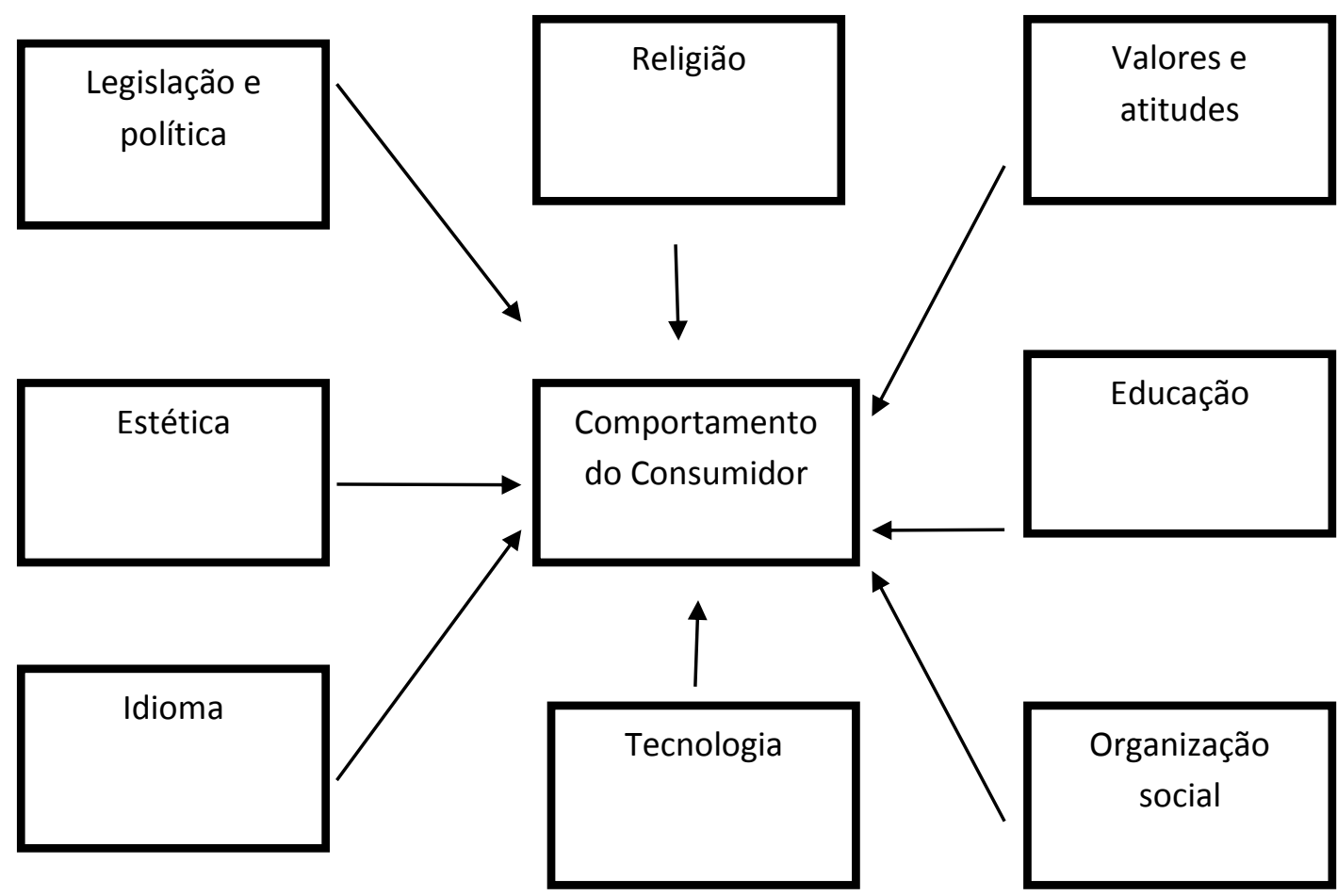

Figura 1 - Fatores de diferenciação cultural Fonte: Manuel e Palacios (2009).

Para Favero (1999), é imprescindível conhecer hábitos7, $\operatorname{costumes}^{8}$, valores culturais como idioma, religião, organização social

$7 \quad$ O conceito de hábitos surge da necessidade de aprender as relações entre o comportamento dos indivíduos e as estruturas e condições sociais. Bourdieu (1983, p. 65), compreende Habitus como um sistema de disposições duráveis e transponíveis que, integrando todas as experiências passadas, funcionam a cada momento como uma matriz de percepções, de apreciações e de ações - e torna possível a realização de tarefas infinitamente diferenciadas, graças às transferências analógicas de esquemas.

8 Lakatos \& Marconi (1999) ensinam: Tipos: Folkways, Mores e Leis A maneira de viver de um grupo social implica normas de comportamento, muitas delas estabelecidas $\mathrm{h}$ tempos atrás. As normas de comportamento social foram classificadas por Sumner em duas categorias diferentes: os folkways (usos) e os 
Artigo original

Hegemonia - Revista Eletrônica de Relações Internacionais do Centro Universitário Unieuro

ISSN: $1809-1261$

UNIEURO, Brasília, número 10, 2012, pp. 49-76.

do mercado comprador, os quais, em certos casos, determinarão condições especiais para o processo de produção, de armazenagem e embalagem do produto.

De acordo com Palacios (2009), para que uma empresa se internacionalize, não é o necessário ser competitiva, ter boa motivação ou aproveitar uma oportunidade excelente; é imprescindível que sua cultura prevalecente seja propícia à implementação de uma postura internacional.

Para Kotler (2000), os fatores sociais e culturais exercem a mais ampla e profunda influência no comportamento do consumidor ${ }^{9}$. Pode-se dizer que o homem é produto do meio em que vive, ou seja, tudo que ocorre no lugar onde as pessoas vivem, exerce influência diretamente na forma como os indivíduos irão pensar e agir.

Barros (2001) enfatiza que em operações onde as

mores (costumes). Esta divisão dos padrões de comportamento se estende, portanto, desde os de menor importância até os obrigatórios e universais. Entre os usos mais frouxos e os costumes mais rigorosos forma-se um contínuo que, tendo-se em vista as variedades dentro de cada categoria, dificulta a delimitação das fronteiras entre um e outro. Essa passagem, fluida e imprecisa, torna difícil classificar alguns padrões situados nesse contínuo, por parecer pertencerem às duas categorias. Nesse caso temos as regras sobre o recato no trajar, o consumo de bebidas alcoólicas etc. Folkways. Padrões não obrigatórios de comportamento social exterior constituem os modos coletivos de conduta, convencionais ou espontâneos, reconhecidos e aceitos pela sociedade. Praticamente, regem a maior parte da nossa vida cotidiana, sem serem deliberadamente impostos. Mores. "São as normas moralmente sancionadas em vigor". Constituem comportamento imperativo, tido como desejável pelo grupo, apesar de restringir e limitar a conduta.

9 O comportamento do consumidor é caracterizado como um processo que vai da seleção de um produto ao consumo do mesmo. Conhecer seu público alvo e trabalhar para atender suas necessidades, hábitos e desejos são fundamentais para uma empresa se diferenciar dos demais concorrentes e motivar os consumidores a utilizarem seus produtos e serviços. 
Artigo original

Hegemonia - Revista Eletrônica de Relações Internacionais do Centro Universitário Unieuro

ISSN: $1809-1261$

UNIEURO, Brasília, número 10, 2012, pp. 49-76.

nacionalidades das empresas e o país-alvo são distintas, o choque cultural é muito grande. Todas as organizações carregam consigo traços da cultura de seus países. Dentre esses traços, os que geralmente tornam as relações mais complexas são o idioma e os costumes e práticas de gestão. Ainda segundo o autor, para uma correta avaliação cultural, não é bastante conhecer apenas a cultura do país alvo. A empresa que busca internacionalizar suas operações precisa enxergar nitidamente sua própria cultura e compreendê-la em sua totalidade.

Mazzola10 (2008) afirma que diversos estudos de caso têm evidenciado que empresas com vocação internacional, geralmente possuem sua cultura interna definida e coerente com essa linha de atuação, através da qual as pessoas são valorizadas, o compartilhamento de conhecimento coletivo é incentivado, a inovação é estimulada, o enfrentamento de riscos é feito dentro de riscos calculados, há uma constante busca na excelência organizacional e sempre perseguem as mais altas posições de liderança nos mercados onde atuam.

2.5- Fatores legais e políticos

Para Favero (1999) os obstáculos que podem comprometer o

$10 \quad$ Disponível em

http://www.pro.poli.usp.br/ginebra/referencias/dissertacoes/Dissertacao\%20Mestra do\%20Homero\%20Jorge\%20Mazzola.pdf . 
Artigo original

Hegemonia - Revista Eletrônica de Relações Internacionais do Centro Universitário Unieuro

ISSN: $1809-1261$

UNIEURO, Brasília, número 10, 2012, pp. 49-76.

êxito de uma operação de exportação são, às vezes, causados por problemas internos ao país ou inerentes ao país do cliente comprador. O autor cita, entre outras barreiras, a ausência de uma política de comércio exterior e de incentivos fiscais e financeiros às exportações, instabilidade econômica do país, altas tarifas alfandegárias, taxas e quotas ou regulamentação excessivamente protecionista.

Favero (1999) afirma ainda que por outro lado, o desconhecimento do mercado internacional e o despreparo da empresa exportadora ou do importador também representam obstáculos que podem resultar no insucesso da negociação.

Segundo Palácios (2009), quer queira ou não, na hora de realizar negócios em qualquer país, será sempre o seu governo quem irá conceder ou não maior ou menor liberdade. Assim, o conhecimento da política e da legislação dos países que se pretende atuar é um fator importante.

Kotler (1998) recomenda que futuros exportares se atentem aos seguintes fatores:

A atitude face aos produtos e investimentos estrangeiros - ao venderem para outros países, as empresas têm que enfrentar diversas restrições comerciais. Ainda segundo o autor, dentre essas restrições estão as tarifas, cotas e até mesmo embargos. Algumas empresas também têm que enfrentar os controles de câmbio e barreiras comerciais não tarifárias, como a discriminação contra a oferta de seus produtos. (...) A estabilidade política - a instabilidade de um país afeta diretamente a forma como a empresa vai lidar com os negócios e problemas financeiros.(...) 
Artigo original

Hegemonia - Revista Eletrônica de Relações Internacionais do Centro Universitário Unieuro

ISSN: $1809-1261$

UNIEURO, Brasília, número 10, 2012, pp. 49-76.

A regulamentação monetária - uma grande parte do comércio internacional envolve transações em dinheiro, no entanto tornou-se como a prática chamada contertrade que possui várias modalidades: o escambo; a compensação (ou recompra), onde o vendedor vende uma máquina e tecnologia e aceita como pagamento os produtos resultantes; e a contracompra, em que o país recebe o pagamento em dinheiro mas promete gastar parte deste dinheiro no país comprador em determinado período de tempo. (...) A burocracia administrativa - o quarto fator se refere à forma como o governo importador administra um sistema eficiente para ajudar empresas estrangeiras: uma alfândega eficaz, informação apurada do mercado e outros fatores que convergem para a realização dos negócios. (Kotler, 1998 p. 77-80).

Portanto, os autores alertam para o que é a concorrência no mercado internacional.

3- Concorrência no mercado externo

Palácios (2009) destaca que todo planejamento deverá ser direcionado levando em conta a concorrência no mercado externo ou mesmo na concorrência interna, as empresas deverão estar atentas a novos produtos ou novos processos utilizados pelos seus concorrentes. Ainda segundo o autor, uma análise constante e 
Artigo original

Hegemonia - Revista Eletrônica de Relações Internacionais do Centro Universitário Unieuro

ISSN: $1809-1261$

UNIEURO, Brasília, número 10, 2012, pp. 49-76.

criteriosa poderá resultar em aproveitamento de novas oportunidades de negócios, em melhoria de procedimentos operacionais ou mesmo em reorientações estratégicas com reflexos no fortalecimento empresarial.

Porter (1987) sugere que existem cinco forças que determinam a rentabilidade de uma empresa em um mercado. A ideia é de que cada empresário avalie os seus objetivos e recursos em função das cinco forças que regulamentam a competitividade industrial:

1. A rivalidade com os concorrentes existentes;

2. A ameaça de novos produtos ou serviços substitutos;

3. A ameaça da entrada de novos concorrentes;

4. O poder dos clientes;

5. O poder de negociação dos concorrentes.

A concorrência, segundo Porter, resulta da interação entre as forças de mercado, como se esquematiza na figura 2. 
Artigo original

Hegemonia - Revista Eletrônica de Relações Internacionais do Centro Universitário Unieuro

ISSN: $1809-1261$

UNIEURO, Brasília, número 10, 2012, pp. 49-76.

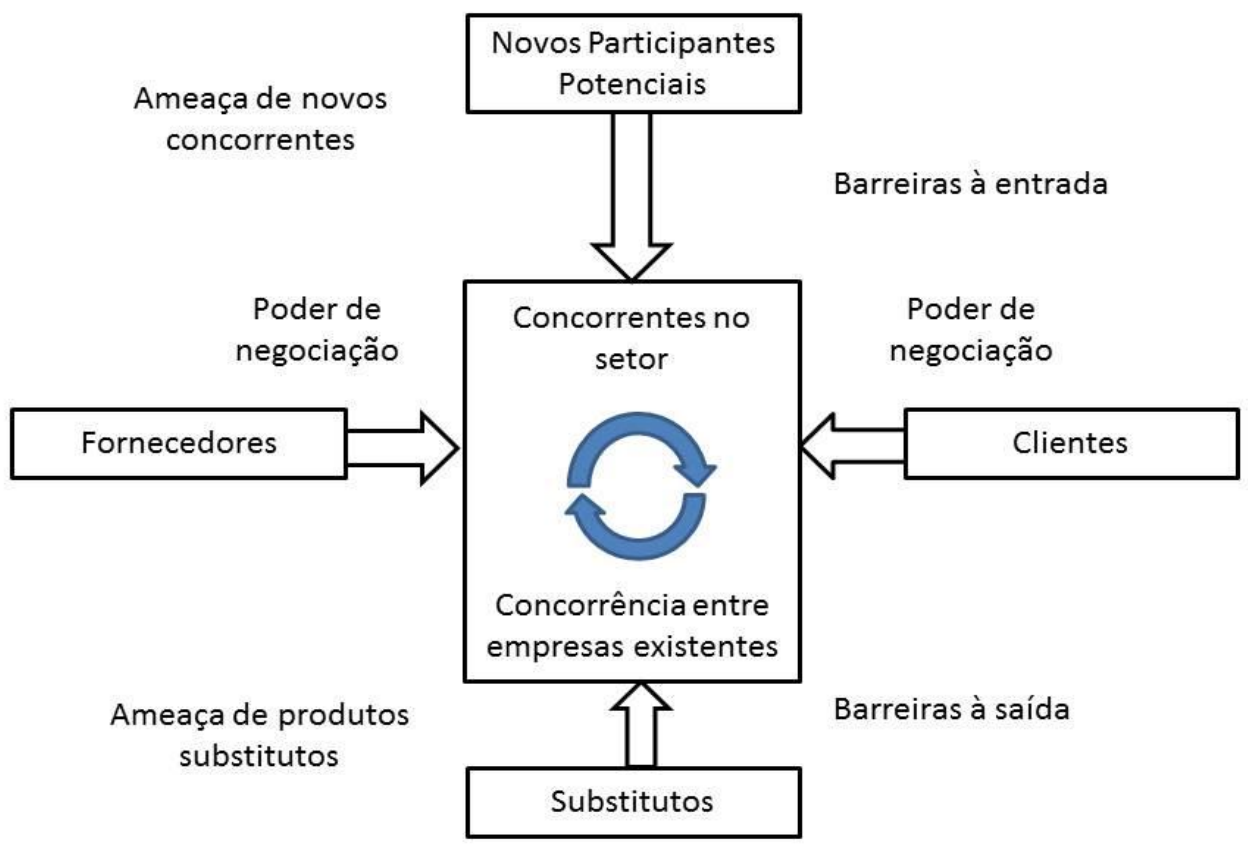

Figura 2 - As cinco forças da concorrência. Fonte: Adaptada de Michael Porter, Estratégia Competitiva (1997)

Porter (1997) deixa claro que a analise das forças de mercado mostram-nos a possibilidade real de criar utilidade na indústria, dependendo a diferenciação da empresa, em relação aos seus concorrentes, de:

- Sua posição competitiva ${ }^{11}$;

- Sua proposta de valor ${ }^{12}$;

11 As empresas devem ter a preocupação de criarem uma posição competitiva no mercado, o que está diretamente relacionado à gestão de custos, diferenciação da empresa frente a seus concorrentes e o foco da empresa (especialização em segmentos ou nichos específicos). 
Artigo original

Hegemonia - Revista Eletrônica de Relações Internacionais do Centro Universitário Unieuro

ISSN: $1809-1261$

UNIEURO, Brasília, número 10, 2012, pp. 49-76.

- Um desempenho superior aos demais concorrentes, derivado das suas atividades complementares.

Segundo Palácios (2009), convêm realçar a importância da determinação da proposta de valor em mercados exteriores, que é a promessa que a empresa faz de entregar aos seus clientes uma combinação única de valores (preço, qualidade, seleção, benefício total etc.) e convencê-los de que a oferta é melhor do que a da concorrência.

\section{CONSIDERAÇÕES FINAIS}

O principal objetivo deste artigo foi entender a importância do prévio estudo de mercado quando da implantação de empresas no exterior, o que nos levou a uma profunda pesquisa sobre o tema.

O estudo indica que cerca de $70 \%$ das empresas brasileiras que fecham as portas são por falta de preparo e controle gerencial. Este fato indica que a falta de conhecimento do mercado em que atuam ou pretendem atuar é fator crucial para sobrevivência das empresas.

O primeiro passo foi identificar, através de estudos sobre o tema, as variáveis que podem ser decisivas neste processo. Um

\footnotetext{
12 Valor é aquilo que os compradores estão dispostos a pagar pelo que a empresa Ihes oferece, ou seja, cada indivíduo estabelece o valor do produto ou serviço adquirido em função do benefício agregado por este produto ou serviço. Kotler (2000 p.33), define valor como a razão entre o que o cliente recebe e o que ele dá. O cliente recebe benefícios e assume custos. Os benefícios incluem benefícios funcionais e emocionais. Os custos incluem custos monetários, de tempo, de energia e psicológicos.
} 
Artigo original

Hegemonia - Revista Eletrônica de Relações Internacionais do Centro Universitário Unieuro

ISSN: $1809-1261$

UNIEURO, Brasília, número 10, 2012, pp. 49-76.

conjunto de seis características foi identificado: fatores econômicos, moeda, fatores tecnológicos, socioculturais, fatores legais e políticos e a concorrência. Em seguida, cada uma foi estudada individualmente.

Cada variável analisada indica o quanto é importante para futuros exportadores conhecerem bem o mercado em que desejam atuar e principalmente conhecer seus limites e potencialidades. Um estudo aprofundado fornece informações a respeito de um país que tanto podem ser uma oportunidade para as empresas como podem revelar seus pontos fracos.

Uma análise completa e constante do ambiente econômico pode antever situações que podem desestabilizar a empresa. Atentar para fatores como inflação, moeda, impostos, restrições comerciais e indicadores de riscos podem deixar os futuros exportadores mais preparados para enfrentarem o desconhecido. A disposição dos consumidores para adquirirem bens e serviços também deve ser levada em conta, pois, em países onde os índices de instabilidade e recessões estão altos, os consumidores tendem a gastar menos.

Os fatores tecnológicos têm influência direta nos custos de uma empresa. Ao investir em tecnologia, as empresas adquirem processos mais baratos e eficientes; fortalecem sua posição no mercado doméstico e ainda aumentam seu nível de competitividade nos mercados internacionais. Os benefícios de absorver novas tecnologias são refletidos em preços mais competitivos, aumento na qualidade dos produtos e serviços e no aperfeiçoamento dos métodos 
Artigo original

Hegemonia - Revista Eletrônica de Relações Internacionais do Centro Universitário Unieuro

ISSN: $1809-1261$

UNIEURO, Brasília, número 10, 2012, pp. 49-76.

administrativos.

Os futuros exportadores devem levar em conta todas as influências sociais e culturais de seu mercado-alvo. Fazer uma análise detalhada da cultura de um país é primordial para a adaptação da empresa à realidade do país. A identidade de um país está exatamente em sua cultura, o que é um fator de diferenciação de cada país. Os fatores socioculturais irão determinar como as pessoas em cada país vivem e se relacionam com as ofertas do mercado comercial.

Na maioria dos casos as empresas devem adaptar seus produtos e processos para agradarem os consumidores. As empresas devem estar preparadas para se adaptarem em mercados externos, pois isto requer uma mudança na cultura da organização e mais investimentos.

Possuir um amplo conhecimento da política e da legislação dos países em que se deseja atuar é um fator importante, pois para a negociação em países estrangeiros será sempre o governo local quem irá regular todas as atividades. Alguns países apresentam restrições e barreiras comerciais, enquanto outros são mais abertos à negociação ou até mesmo fazem parte de acordos de cooperação comercial. Começar exportando para países que participam de acordos comerciais com o país de origem da empresa pode proporcionar mais segurança e maiores chances de retorno para a empresa.

O estudo da concorrência antes de investir em mercados estrangeiros pode proporcionar às empresas informações importantes 
Artigo original

Hegemonia - Revista Eletrônica de Relações Internacionais do Centro Universitário Unieuro

ISSN: $1809-1261$

UNIEURO, Brasília, número 10, 2012, pp. 49-76.

para a formulação de estratégias de entrada. Dar a devida atenção aos fatores que Porter (1987) considera como as cinco forças da concorrência, reflete diretamente na rentabilidade das empresas. A empresa se colocando em uma posição competitiva e gerando valor para os clientes tem maiores chances de sobrevivência em mercados altamente competitivos.

Ficou comprovado com o estudo que a análise de mercado é uma etapa do processo de internacionalização que não pode ser esquecida. Como cada país possui a sua identidade, isto exige ações mais direcionadas e personalizadas para cada mercado. Empresários capacitados têm chances reais de se estabelecerem no exterior e obterem sucesso em suas operações.

O trabalho indica que ainda falta muito estudo sobre o assunto pesquisado, pois foram encontradas dificuldades para encontrar autores abordando a necessidade do estudo das variáveis mercadológicas relacionadas ao comércio internacional. A maioria dos dados encontrados foram de autores da área de marketing, o que gerou maior dificuldade para relacionar as informações encontradas.

Não se teve, neste estudo a intenção de se esgotar o tema, muito menos de expor conceitos absolutos e inquestionáveis. Todas as reflexões aqui expostas são passíveis de considerações e mudanças. As considerações se fecham, neste momento, mas estão abertas para futuros questionamentos. 
Artigo original

Hegemonia - Revista Eletrônica de Relações Internacionais do Centro Universitário Unieuro

ISSN: $1809-1261$

UNIEURO, Brasília, número 10, 2012, pp. 49-76.

\section{REFERENCIAL BIBLIOGRÁFICO}

\section{APRENDENDO A EXPORTAR}

http://www.aprendendoaexportar.gov.br/sitio/paginas/plaExportacao/ index.html Acesso em: 07/09/2011 às 17h29

BANEGIL PALACIOS, Tomás Manuel, José M. Meirelles de Sousa, Estratégias de Marketing Internacional. São Paulo: Editora Atlas, Edição 2004.

BARROS, Betânia Tanure de. Encontro das culturas organizacionais. In: Barros, Betânia Tanure de (Org.). Fusões, aquisições \& parcerias. São Paulo: Atlas, 2001.

BOURDIEU, Pierre, (1963). Travail ET Travailleurs em Algérie. Paris: Mouton.

Ática.

(1983) Sociologia. (organizado por Renao Ortiz) São Paulo:

CATEORA, Philip R. Marketing Internacional. São Paulo, LTC, 2099. $13^{a}$ edição.

DRUCKER, Peter F. Administrando em tempos de grandes mudanças. São Paulo, Pioneira, 1995.

FAE. http://www.fae.edu/publicacoes/pdf/mkt/1.pdf Acesso em 09/11/2011 às 09h26

FAVERO, Isabel (org.). Manual básico de exportação. Recife: MRE: SEBRAE, 1999

FERRELL, O. C. - Estratégia de marketing / Michael D. Hartline - São Paulo: Pioneira Thomson Learning, 2009. 
Artigo original

Hegemonia - Revista Eletrônica de Relações Internacionais do Centro Universitário Unieuro

ISSN: $1809-1261$

UNIEURO, Brasília, número 10, 2012, pp. 49-76.

FLEURY, Maria Tereza Leme e FISCHER, Rosa Maria (org). Cultura e poder nas organizações. São Paulo, Atlas, 1990.

IBGE.http://www.ibge.gov.br/home/estatistica/pesquisas/pesquisa_re sultados.php?id_pesquisa=9 Acesso em 25/10/2011 às 19 h45

KAPLAN, Robert S.; Norton, David P. A Estratégia em ação: balanced scorecard. Trad. Luiz Euclides Trindade Frazão Filho. Rio Janeiro: Elsevier, 1997. Original: The balanced scorecard.

KEEGAN, Warren J. Princípios de Marketing Global. 7. Ed. São Paulo: Prentice Hall, 2005

KOTLER, Philip. Administração de marketing. 5 ed. São Paulo: Atlas, 1998.

LAKATOS, Eva M.; Marconi, Mariana A. Sociologia Geral. 7 ed. São Paulo: Atlhas, 1999.

MELANDER FILHO, Eduardo. A Cultura Segundo Edward B. Tylor e Franz Boas. Gazeta de Interlagos, São Paulo, 13 mar 2009 a 26 mar 2009. História, p. 2.

MINERVINI, Nicola. O exportador. Ferramentas para atuar com sucesso nos mercados internacionais. 3 ed. São Paulo: Makron Books, 2001.

MINERVINI, Nicola. Exportar: Competitividade e Internacionalização. São Paulo: Makron Books Brasil, 1997.

PALACIOS, Tomás Manuel B., SOUZA, José Manuel M. de. Estratégias de Marketing Internacional. 1 ed. São Paulo: Editora Atlas, 2009.

PORTER, Michael E. Estratégia competitiva: técnicas para analise de industrias e da concorrência. 7.ed. Rio de Janeiro: campus, 1997.362 p.

PRO.http://www.pro.poli.usp.br/ginebra/referencias/dissertacoes/Diss ertacao\%20Mestrado\%20Homero\%20Jorge\%20Mazzola.pdf Acesso 
Artigo original

Hegemonia - Revista Eletrônica de Relações Internacionais do Centro Universitário Unieuro

ISSN: $1809-1261$

UNIEURO, Brasília, número 10, 2012, pp. 49-76.

em $07 / 11 / 2011$ às $12 \mathrm{~h} 50$.

RATTI, Bruno. Comércio Internacional e Câmbio. 10. Ed. São Paulo: Aduaneiras, 2001.

SANTOS, José Luiz dos. O que é cultura. $11^{\mathrm{a}}$ ed. São Paulo, Brasiliense, 1983.

SOBEET. Internacionalização das Empresas Brasileiras. São Paulo: Clio Editora, 1 aEdição. 